\title{
Pengetahuan dan Sikap Wanita Premenopause dalam Menghadapi Perubahan-Perubahan pada Masa Menopause
}

\author{
Ria Afriani ${ }^{1}$, Tina Yuli Fatmawati ${ }^{2}$ \\ ${ }^{1}$ Program studi DIII Kebidanan STIKes Baiturrahim \\ ${ }^{2}$ Program studi DIII Keperawatan STIKes Baiturrahim \\ Email: Tinayulifatmawati@gmail.com
}

Submitted : 04/02/2020

Accepted: 06/02/2020

Published: 14/03/2020

\begin{abstract}
Abstrack
Elderly women are found around 8-10\% in the State of Indonesia whose health must get the attention of the community so that happiness and well-being are achieved. A woman at a certain age will experience climacteria where there is a natural change in her body. Changes that occur during menopause consist of short-term effects can cause discomfort in everyday life. This research is a descriptive study to find out the description of knowledge and attitudes of premenopausal women in dealing with changes during menopause. The population in this study were all preelderly women at the Kenali Besar Health Center in Jambi City. The samples taken by accidental sampling technique amounted to 44 people. This research was conducted in 2019 at the Kenali Besar Health Center in Jambi City. Data collection through interviews using a questionnaire. Data were analyzed univariately. The results were obtained from 44 respondents, 17 respondents (39\%) had good knowledge, 11 respondents (25\%) had enough knowledge and 16 respondents (36\%) had poor knowledge. The results of attitudes obtained most of the respondents have a negative attitude that is 22 respondents (55\%), positive attitudes as many as 20 respondents (45\%).
\end{abstract}

Keywords: attitudes, changes in menopause, knowledge

\begin{abstract}
Abstrak
Wanita usia lanjut dijumpai sekitar $8-10 \%$ di Negara Indonesia yang kesehatannya harus mendapatkan perhatian dari masyarakat sehingga tercapai kebahagiaan serta kesejahteraan. Seorang wanita pada usia tertentu akan mengalami klimakterium dimana terjadi perubahan alamiah dalam tubuhnya. Perubahan yang terjadi pada masa menopausebisa menimbulkan ketidaknyamanan dalam kehidupan sehari-hari. Penelitian ini merupakan penelitian deskriptif untuk mengetahui gambaran pengetahuan dan sikap wanita premenopause dalam menghadapi perubahan-perubahan pada masa menopause. Populasi dalam penelitian ini adalah seluruh wanita pra lansia di Puskesmas Kenali Besar Kota Jambi. Sedangkan sampel diambil dengan teknik accidental sampling berjumlah 44 orang. Penelitian ini dilakukan pada tahun 2019 di Puskesmas Kenali Besar Kota Jambi. Pengumpulan data melalui wawancara menggunakan kuesioner dan dianalisis secara univariat. Hasil penelitian diperoleh dari 44 responden, 17 responden (39\%) memiliki pengetahuan baik, 11 responden (25\%) memiliki pengetahuan cukup dan 16 responden (36\%) memiliki pengetahuan kurang baik. Hasil sikap didapat sebagian besar responden memiliki sikap negative yaitu 24 responden (55\%), sikap positif sebanyak 20 responden (45\%).
\end{abstract}

Kata Kunci: pengetahuan, perubahan masa menopause, sikap

\section{PENDAHULUAN}

Masa usia lanjut merupakan periode penutup dalam rentang hidup seseorang. Pada masa usia lanjut seseorang akan mengalami proses penuaan secara terus menerus yang ditandai dengan menurunnya daya tahan fisik yaitu semakin rentan terhadap serangan penyakit yang dapat menyebabkan kematian. Hal ini disebabkan oleh perubahan dalam struktur dan fungsi sel, jaringan dan sistem organ (Irianto, 2015). 
Menurut World Health Organization (WHO), di kawasan Asia Tenggara populasi Lansia sebesar $8 \%$ atau sekitar 142 juta jiwa. Pada tahun 2050 diperkirakanpopulasi Lansia meningkat 3 kali lipat dari tahun ini. Pada tahun 2000 jumlah Lansia sekitar 5.300.000 (7,4\%) dari total populasi, sedangkan pada tahun 2010 jumlah Lansia 24.000.000 (9,77\%) dari total populasi, dan tahun 2020 diperkirakan jumlah Lansia mencapai 28.800 .000 $(11,34 \%)$ dari total populasi.

Berdasarkan data yang didapat dari Profil Kesehatan Indonesia Tahun 2017 didapat bahwa jumlah penduduk usia 40-49 sebanyak 17.028.035, penduduk usia 50-54 tahun berjumlah 14.601.469, penduduk usia 55-59 tahun berjumlah 11.903.287, penduduk usia 60-64 tahun berjumlah 8.870.493, penduduk usia 65-69 tahun berjumlah 6.035.413, dan usia $>70$ tahun sebanyak 8.752.308 (Kemenkes RI, 2017).

Wanita usia lanjut akan dijumpai sekitar 8-10\% di Negara Indonesia yang kesehatannya harus mendapatkan perhatian dari masyarakat sehingga tercapai kebahagiaan serta kesejahteraan. Seorang wanita pada usia tertentu akan mengalami klimakterium dimana terjadi perubahan alamiah dalam tubuhnya (Prasetyawati, 2012).

Perubahan-perubahan pada struktur dan fisiologis dari berbagai sel/jaringan/organ dan sistem yang ada pada tubuh manusia. Proses ini menjadikan kemunduran fisik maupun psikis. Kemunduran fisik ditandai dengan kulit mengendur, rambut memutih, penurunan pendengaran, penglihatan memburuk, gerakan lambat dan kelainan berbagai fungsi organ vital. Sedangkan kemunduran psikis terjadi peningkatan sensitivitas emosional, menurunnya gairah, bertambahnya minat terhadap diri, berkurangnya minat terhadap penampilan, meningkatnya minat terhadap material, dan minat rekreasi (Mubarak, 2009).
Perubahan yang terjadi pada masa menopause terdiri dari dampak jangka pendek seperti pada perubahan fisik perubahan kulit, lemak bawah kulit berkurang sehingga kulit menjadi kendur, kulit mudah terbakar sinar matahari dan menimbulkan pigmentasi dan menghitam, otot bawah kulit wajah mengendur sehingga jatuh dan lembek, keadaan ini bisa menimbulkan ketidaknyamanan dalam kehidupan sehari-hari. Sedangkan pada perubahan psikologi yaitu merasa tua, tidak menarik lagi, rasa tertekan karena takut menjadi tua, mudah tersinggung, mudah terkejut sehingga jantung berdebar-debar, takut tidak dapat memenuhi kebutuhan seksual suami, rasa takut bahwa suami akan menyeleweng, keinginan seksual menurun dan sulit mencapai kepuasan (orgasme), merasa tidak berguna dan tidak menghasilkan sesuatu, merasa memberatkan keluarga dan dampak panjang yaitu adanya penyakit osteoporosis, penyakit jantung koroner dan kepikunan (dimensia) (Kumalasari, 2012).

Penelitian sebelumnya yang dilakukan oleh Arifarahmi, 2019 hasil penelitiannya diperoleh bahwa sikap wanita terhadap keluhan masa menopause masih kurang baik (55\%). Mengingat besarnya dampak yang diakibatkan dari menopause sehingga perlunya upaya dalam meningkatkan pengetahuan ibu sehingga ibu dapat bersikap positif dalam menghadapi masa premenopause.

\section{METODE PENELITIAN}

Penelitian ini telah dilakukan di Puskesmas Kenali Besar Kota Jambi pada tahun 2019. Jenis penelitian yang digunakan adalah penelitian kuantitatif bersifat deskriptif untuk mengetahui gambaran pengetahuan dan sikap wanita premenopause dalam menghadapi perubahan-perubahan pada masa menopause di Puskesmas Kenali Besar Kota Jambi Tahun 2019. Populasi dalam penelitian ini adalah seluruh wanita pra 
lansia di Puskesmas Kenali Besar Kota Jambi yang berjumlah 3.295 orang. Sampel dalam penelitian ini adalah sebagian wanita pra lansia di Puskesmas Kenali Besar Kota Jambi yang berjumlah 3.295 orang. Cara pengambilan sampel menggunakan tekhnik accidental sampling yaitu pengambilan sampel yang kebetulan ditemui peneliti pada saat penelitian di lakukan.

Teknik pengumpulan data dengan menggunakan kuesioner yang berisi mengenai pertanyaan pengetahuan dan pernyataan sikap. Pada pengetahuan terdiri dari 18 pertanyaan sedangkan pada sikap terdiri dari 18 pernyataan yang terdiri dari pernyataan positif dan pernyataan negatif.

HASIL DAN PEMBAHASAN

Tabel 1. Distribusi Pengetahuan Wanita Premenopause Dalam Menghadapi Perubahan-Perubahan Pada Masa Menopause

\begin{tabular}{lcc}
\hline Pengetahuan & $\mathrm{f}$ & $\%$ \\
\hline Kurang Baik & 16 & 36 \\
Cukup & 11 & 25 \\
Baik & 17 & 39 \\
Total & 44 & 100 \\
\hline
\end{tabular}

Berdasarkan tabel diatas dapat diketahui bahwa dari 44 responden. 17 responden (39\%) yang memiliki pengetahuan baik, 11 responden (25\%) yang memiliki pengetahuan cukup dan 16 responden $(36 \%)$ yang memiliki pengetahuan kurang baik.

Hasil penelitian yang dilakukan oleh Rakuea (2016) mengenai gambaran pengetahuan wanita tentang menopause di Dukuh Sorobaon Kelurahan Jati Kecamatan Jaten Kabupaten Karangayar didapat bahwa sebanyak $61,8 \%$ responden memiliki pengetahuan baik dan $38,2 \%$ memiliki pengetahuan kurang baik. Hasil penelitian Ridwan (2015) mengenai hubungan antara pengetahuan dengan sikap ibu tentang perubahan fisik menopause di dusun Ngesong desa Banjarejo sebanyak 32 responden $(54 \%)$ memiliki pengetahuan kurang, sedangkan sebagian kecil yaitu 11 responden (19\%) memiliki pengetahuan baik.

Pengetahuan responden dapat dipengaruhi oleh umur responden. Karena sebagian besar responden berusia 4549tahun sehingga dengan usia tersebut responden yang belum mendapatkan menopouse belum banyak mendapatkan informasi dan pengalaman terkait tentang perubahan masa menopouse. Menurut Utami (2017), makin bertambahnya umur seseorang, pengalamannya akan bertambah sehingga akan lebih siap dalam menghadapi menopause. Umur seseorang berkaitan dengan bertambahnya pengalaman, dimana pengalaman tersebut akan meningkatkan pengetahuan dan kematangan seseorang dalam menghadapi masalah yang terjadi dalam kehidupan.

Selain itu, pengetahuan juga dapat dipengaruhi oleh pendidikan karena didapat bahwa sebagian besar responden berpendidikan SMA/sederajat sebanyak 52,3\% Menurut Wawan (2010), pada umumnya semakin tinggi pendidikan seseorang makin mudah untuk menerima informasi. Hal ini menunjukkan bahwa pengetahuan responden yang baik karena sebagian besar responden memiliki pendidikan menengah. Semakin tingginya pendidikan responden maka membuat responden akan mudah mendapatkan informasi mengenai perubahan masa menopouse.

Pekerjaan juga dapat mempengaruhi pengetahuan yang dimiliki responden. Dalam penelitian ini sebagian besar responden merupakan ibu rumah tnagga sebanyak 97,7\%. Menurut Ariani (2014), pekerjaan merupakan salah satu faktor yang mempengaruhi pengetahuan. Hal ini menunjukkan bahwa pola kerja sebagai ibu rumah tangga, menyebabkan waktu ibu untuk mencari informasi tentang menopause, misalnya dengan membaca buku, mendatangi petugas kesehatan dan sebagainya dapat menjadi lebih sering. 
Dapat disimpulkan bahwa sebagian responden memiliki pengetahuan yang baik dan sebagain lagi kurang baik tentang perubahan masa menopouse. Hal ini dapat dipengaruhi dari informasi yang belum didapatkan responden dari petugas kesehatan, teman, keluarga maupun informasi melalui media perubahan masa menopause. Selain itu masih banyak responden yang belum mengalami keluhankeluhan tersebut sehingga belum memiliki pengalaman dan belum mendapatkan informasi.

Untuk meningkatkan pengetahuan responden maka sangat dibutuhkan peran dari tenaga kesehatan untuk memberikan penyuluhan mengenai perubahan masa menopouse pada masyarakat khususnya pada wanita premenopuse sehingga dengan mengetaui perubahan masa menopouse maka responden dapat menerima dan dapat mengatasinya dengan baik.

Selain itu sebaiknya pihak puskesmas memberikan pendidikan kesehatan mengenai perubahan masa menopouse yang dapat dipasang melalui poster-poster yang berisi tentang kesehatan lansia khususnya mengenai perubahan masa menopouse Sehingga dengan menggunakan media yang menarik akan meningkatkan minat baca masyarakat sehingga dapat meningkatkan pengetahuan masyarakat khususnya wanita premenopouse tentang perubahan masa menopause.

Berdasarkan tabel 2 dapat diketahui bahwa dari 44 responden sebagian besar responden memiliki sikap negatif yaitu 24 responden $(55 \%)$ dan responden yang memiliki sikap baik sebanyak 20 responden $(45 \%)$.

Tabel 2. Distribusi Sikap Wanita Premenopause Dalam Menghadapi Perubahan-Perubahan Pada Masa Menopause di Puskesmas Kenali Besar

\begin{tabular}{lcc}
\hline Sikap & f & $\%$ \\
\hline Negatif & 24 & 55 \\
Positif & 20 & 45 \\
\hline Total & 44 & 100 \\
\hline
\end{tabular}

Hasil penelitian yang dilakukan oleh Kumalasari (2014) mengenai Sikap Wanita Menopause Tentang Perubahan Fisik Pada Masa Menopause di Desa Gayaman Kecamatan Mojoanyar Kabupaten Mojokerto didapat bahwa sebagian besar responden memiliki sikap negatif dalam menghadapi perubahan fisiologi pada masa menopause di Desa Gayaman Kecamatan Mojoanyar Kabupaten Mojokerto yaitu 41 orang $(52,6 \%)$.

Sikap yang negatif juga dapat dipengaruhi oleh umur responden karena sebagian besar dalam penelitian ini responden berusia 51-55 tahun. Dengan usia yang memasuki masa lansia maka banyak responden yang telah mengalami perubahan masa menopouse namun tidak menyetujui dengan pernyataan-pernyataan yang diberikan. Sehingga masih beranggapan negatif terhadap perubahan masa menopause. Sikap yang negatif dapat pula dipengaruhi oleh pengetahuan responden yang masih kurang baik. Pengetahuan responden yang kurang terhadap keluhan menopause membuat responden tidak mengetahui hal yang akan terjadi dan dialami pada masa menopause sehingga membuatnya beranggapan negatif terhadap perubahan masa menopause. Selain itu sikap yang negatif dapat pula disebabkan karena responden belum pernah mengalami hal-hal atau perubahanperubahan pada masa menopouse.

Sikap yang positif dapat pula dipengaruhi oleh beberapa jawaban responden yang menjawab setuju tentang wanita yang memasuki masa menopause tidak perlu melakukan pemeriksaan pap semar sebanyak $45,5 \%$ dan wanita yang memasuki masa menopause tidak perlu melakukan pemeriksaan pap smear sebanyak 47,7\%. Dalam hal ini menunjukkan bahwa masih terdapat responden yang tidak mengetahui perubahan-perubahan pada masa menopouse sehingga menganggap bahwa wanita menjelang menopouse menjadi lebih 
sabar. Selain itu masih terdapat responden yang tidak mengetahui cara mencegah dampak negatif pada masa menopouse yaitu dengan melakukan papsmear

Sedangkan sikap yang negatif dapat diperoleh dari beberapa jawaban yaitu melakukan olahraga yang berat perlu dilakukan wanita yang memasuki masa menopause sebanyak 14 responden $(21,8 \%)$. Hal inilah yang membuat sikap responden menjadi negatif karena masih dalam masa menopuse sebaiknya responden melakukan olahraga untuk mencegah perubahan-perubahan yang terjadi pada masa menopause.

Maka dari itu, sikap yang baik terhadap perubahan menopause dapat dipengaruhi oleh pengetahuan yang responden miliki mengenai perubahanperubahan masa menopause selain itu sikap yang baik dapat dipengaruhi oleh pengalaman dari diri sendiri maupun orang lain sehingga mempengaruhi sikap responden. Sedangkan sikap yang negatif dapat disebabkan oleh pengetahuan yang kurang serta keluhan yang belum pernah dialami oleh responden sehingga membuat sikapnya menjadi negatif.

Diharapkan wanita yang akan memasuki masa menopause lebih banyak menggali informasi tentang menopause, agar tidak perlu cemas menghadapi menopause. Menopause bukanlah penyakit, oleh karena itu tidak dibutuhkan perawatan khusus, tetapi beberapa gejala yang terkait dengannya dapat diatasi bukan hanya dengan obat-obatan .Menopause merupakan masalah normal, sedangkan penerimaannya bisa berbeda-beda di antara para wanita. Dengan demikian, alangkah baiknya apabila masalah menopause ini diketahui secara jelas oleh setiap wanita di Indonesia. Diharapkan wanita menopasue lebih banyak mencari sumber informasi agar dapat memperbanyak pengetahuan

Oleh karena itu, untuk mengubah sikap wanita menjadi baik terhadap perubahan masa menopause sangat diperlukan informasi mengenai keluhankeluhan masa menopause baik itu keluhan yang akan terjadi, cara mengatasi dan upaya untuk menghadapi masa menopause. Sehingga dengan mengetahui perubahan masa menopause akan meningkatkan pengetahuan ibu sehingga ibu akan lebih siap untuk menghadapi perubahan masa menopause dan merubah sikap

\section{SIMPULAN}

Hasil penelitian dapat disimpulkan bahwa sebagian besar responden memiliki pengetahuan yang baik tentang perubahanperubahan pada masa menopause dan sebagian besar responden memiliki sikap yang negatif tentang perubahan-perubahan pada masa menopause

Bagi pihak Puskesmas diharapkan memberikan edukasi secara rutin mengenai keluhan-keluhan masa menopause pada masyarakat

\section{DAFTAR PUSTAKA}

Ariani, Ayu,.P. 2014. Aplikasi Metodologi Penelitian Kebidanan dan Kesehatan Reproduksi. Nuha Medika. Yogyakarta.

Arifarahmi, 2019. Woman's Attitude About Menopause Complaints At The Public Health Center Kebun Handil Jambi City, Jurnal Akademika Baiturrahim Jambi, Volume 8 No 1 , Maret 2019, http://jab.stikba.ac.id/index.php/jab/arti cle/view/108, diakses Januari 2020

Arikunto, S. 2012. Prosedur Penelitian Suatu Pendekatan Praktek (Edisi Revisi). PT Rineka Cipta. Jakarta.

Hekhmawati. 2016. Gambaran Perubahan Fisik dan Psikologis Pada Wanita Menopause di Posyandu Desa Pabelan. Jurnal. Universitas Muhamadiyah Surakarta.

Hessy. 2018. Hubungan Syndrom Pre Menopause Dengan Tingkat Stres Pada Wanita Usia 40-45 Tahun. Jurnal Kesehatan Al-Irsyad. 
Irianto, 2015. Kesehatan Reproduksi. Salemba Medika. Jakarta.

Kemenkes RI, 2017. Profil Kesehatan Indonesia Tahun 2017. Indonesia.

Kumalasari, Intan. 2012. Kesehatan Reproduksi. Salemba Medika. Jakarta.

Kusmiran, Eni. 2012. Kesehatan Reproduksi Remaja Dan Wanita. Jakarta: Salemba Medika.

Lisnaini. 2010. Hubungan Pengetahuan dan Sikap Ibu Pramenopause Terhadap Perubahan Pada Masa Menopause Di Kelurahan Tegal Sari, Kec.Medan Denai Tahun 2010. Jurnal. Universitas Sumatera Utara.

Mubarak, W.I. 2009. Ilmu Keperawatan Komunitas Konsep dan Aplikasi. Salemba Medika. Jakarta.

Maryam, dkk. 2012. Mengenai Usia Lanjut dan Keperawatannya. Salemba Medika. Jakarta

Notoadmodjo,Soekidjo. 2012. Promosi Kesehatan dan Perilaku Kesehatan. PT Rineka Cipta. Jakarta.

Notoadmodjo,Soekidjo. 2010. Metode Penelitian Kesehatan. PT Rineka Cipta.Jakarta.

Nugroho, Tufan. 2014. Obgyn: Untuk Mahasiswa Kebidanan dan Keperawatan. Yoyakarta: Nuha Medika.

Nugroho, Wahjudi. 2010. Komunikasi dalam Keperawatan Gerontik. EGC. Jakarta.
Prasetyawati, 2012. Kesehatan Ibu dan Anak (KIA). Nuha Medika. Yogyakarta.

Rakuea. 2016. Gambaran Pengetahuan Wanita Tentang Menopause Di Dukuh Sorobaon Kelurahan Jati Kecamatan Jaten Kabupaten Karangayar.Jurnal. Universitas Muhamadiyah. Yogyakarta.

Rina. M. Kunder. 2016.Hubungan Sikap Ibu Premenopause dengan Perubahan yang Terjadi Menjelang Masa Menopause di Kelurahan Woloan1, Kecamatan Tomohan. Universitas SamRatulangi Manado.

SDKI. 2012. Survey Demografi Kesehatan Indonesia. Tahun 2012. Kementerian Kesehatan Indonesia.

Sulistyaningsih. 2011. Metode Penelitian Kebidanan Kuantitatif dan Kualitatif. Graha Ilmu. Yogyakarta.

Suparyanto. 2010. Konsep Lansia. dan Kepatuhan.

(Online) http:dr.Suparyanto.blogspot.com. diakses pada 5 Maret 2019.

Wawan dan Dewi. 2010. Teori Dan Pengukuran Pengetahuan, Sikap Dan Perilaku Manusia. Nuha Medika. Yogyakarta. 